\title{
Practical Teaching System for Electrical Engineering Specialty Based on Engineering Ability Cultivation
}

\author{
HU Xiaoqian, Zhang Lian, Li Shan, Jiang Dongrong \\ School of Electronic Information and Automation, Chongqing University of Technology \\ Chongqing, P.R. China \\ email:hxq@cqut.edu.cn
}

Keywords: engineering ability cultivation; practical teaching system; electrical engineering

\begin{abstract}
In order to adapt to the rapid development of domestic power industry and to meet the new demand on engineering talent of electrical engineering, it is of significance to reform traditional practical teaching system and pay attention to engineering ability cultivation. In this paper, aiming at the new requirement of social development for engineering talent cultivation of electrical engineering field, a diversified and multi-layer practical teaching system is constructed. Through multi-layer of humanistic quality practice, natural science practice and engineering ability practice, diversified methods and means of undergraduates' engineering ability training are discussed, with a result of improved talent cultivation quality.
\end{abstract}

\section{Introduction}

Because of the wide range of knowledge and strong adaptability of electrical engineering specialty, the university students of this specialty are required to master not only the specialized knowledge and technical skill of electrical engineering, but also the basic knowledge and skill of automation and information technology, with the ability of solving wide scope specialized problems involving both the strong electricity and weak electricity. Therefore, besides solid theoretical basis, the graduates of electrical engineering specialty must possess strong engineering practical ability. Facing the demand of power industry development, doing research and exploration on the engineering ability cultivation of electrical engineering undergraduates, and looking for feasible method to improve the undergraduates' engineering ability, is an urgent problem to think over and solve for university's electrical engineering specialty ${ }^{[1,2,3]}$.

\section{Cultivation goal}

In order to adapting to the rapid development of domestic power and related industries and to further meet the requirements of nation and industries for electrical engineering talents, the graduates of electrical engineering specialty must be specialized engineering talents, not only mastering systematic theories, special knowledge and skills of fields including electrical engineering, automation, electronic and computer technology, etc., but also having the working abilities in the above fields including engineering designing, technical development, system operation and maintenance, scientific research, production organization and management. The final goal is to train engineering and management talents with good humanistic quality, team cooperation ability, engineering creative ability and social responsibility for electrical engineering field and industry.

\section{General thought and scheme}

Reforming practical teaching system must take social demand as guidance, with actual engineering as background, engineering technique as main clue, engineering ability training as core, and focusing on improving undergraduates' engineering consciousness, engineering practical and innovative ability. So, the whole reform must be accomplished around the following general thought. 
(1) There is a tight link between education and society. The humanistic quality plays an important role on cultivation and growth of students of science and engineering university. The engineering practice need be combined with humanity society practice in order that students can learn how to behave, how to act and has the ability of adapting to society, with high universal comprehensive quality. (2) Students of electrical engineering specialty should have the key knowledge and ability of their own specialty: mastering basic theory and special knowledge of power system operation including generation, transmission, transformation, regulation and control, utilization of power supply, becoming familiar with related national and international technical standard and industrial laws, having ability of developing, designing, manufacturing, operation and management in electrical engineering and related fields. (3) For the content of engineering, on the one hand, it's important to emphasize comprehensiveness, designing and practicability in order to improve students' ability of problem analyzing and solving. On the other hand, taking employment market as guide, talent cultivation should aim at meeting social needs, and reflect the latest trend of current power technology development. For the form of practice, it's needed to combine with enterprise engineering practice, emphasizing University-Industry Cooperation, with main characteristic of multilevel, multiform.(4) Construct student-oriented practical teaching mode, in order to develop personality, realize individualized education. Focus on the openness and autonomous style of practical links, paying attention to training innovation consciousness, innovation ability and students’ self-learning.ability.

\section{Open and innovative practical teaching system}

On the basis of traditional practical teaching system, we have constructed an "Electrical Engineering practical teaching system of engineering innovative type". From general structure, it includes three layers: humanistic quality practice, natural science practice and engineering ability practice (as shown in Fig 1.). Each layer involves diversified practical methods and means, with diversified testing mode aiming at engineering ability training ${ }^{[4]}$.

\section{A. Humanistic quality practice}

Humanistic education plays a basic and important role in the whole higher education. We strengthen undergraduates' practice in social science, literature and art, etc., mainly consisting of entrance education, military training, social association activities, voluntary labor, and employment education and so on. Through various social practices, train undergraduates' good living and studying habit, strong will, collective consciousness, organization management and interpersonal communication ability, and help to improve undergraduates' comprehensive quality, and to establish right philosophy, sense of value, career conception, and high social responsibility.

\section{B. Natural science practice}

Natural science practice consists of college physical experiments, playing a basic and irreplaceable role in the cultivation of comprehensive quality and innovative ability for science and engineering students. We carry out reform based on traditional college physics experiments. On the one hand, besides traditional basic experiment and verification experiment, we add designing experiment and comprehensive experiment. On the other hand, orienting to each applied speciality, the experiments are integrated into three levels: (1) Basic physical experiment, requiring undergraduates to master basic method, basic instruments and operation of physical experiment. (2) Comprehensive physical experiment oriented to electric information discipline, combining traditional college physical experiment with electrical engineering specialty, laying a good specialty foundation. (3) Open and innovative designing physical experiment, providing excellent students with researching, designing and making experiment, encouraging their innovative consciousness. Through the above multi-level and systematic training of science experimental ability, let undergraduates master basic knowledge, method and skill, and train their exquisite observation and austere thinking ability, laying a solid mathematical and physical basis for the further theoretical and practical study in electrical engineering and related fields. 


\section{Engineering ability Practice}

According to the demand of engineering ability education, taking actual engineering designing and researching ability as key and mainline, by reintegration, unified planning and systematization $^{[5,6]}$, we have constructed a multi-layer engineering ability practice system, as shown in Figure 1. It consists of four layers: "basic specialty training layer- specialty comprehensive training layer- comprehensive engineering ability training layer- innovation research layer", forming omnibearing, multi-layer, hierarchical and systematic training of students' engineering practice ability.

\section{- Specialty Basic Training Layer}

Basic course experiments and practical training of mechanical and electrical information discipline, including engineering drawing, mechanical manufacturing basic training, electrics and electronics skill training, circuit and electronics basic experiment, microcomputer principle and applications experiment, and electronic technology applying design, etc. Students can grasp basic experiment skill and basic engineering ability of electrical information discipline. In addition, by paying attention to computer applying ability, the undergraduates are required to master the frequently used softwares in the fields of engineering drawing and electronic designing, such as Autocad, Protel, Protus, etc.

\section{- Specialty Comprehensive Training Layer}

Comprehensive experiments and course designs of electrical engineering can designedly and systematically form multiform and multilevel engineering practical training in the third year of university, training undergraduates' comprehensive engineering skill.

(1) In the first stage, take course experiments of electrical testing technology, automatic control theory, electromechanics, and power electronic technology as the key. On the one hand, make students direct contact the actual testing and control element and system, having perceptual cognition and elementary training in the fields of sensor, motor, and power electronic device. On the other hand, train undergraduates' ability of computer aided design, for an instance, require undergraduates to skillfully master Matlab, Labview based modeling and simulation of control, signal processing, power system analysis, laying solid foundation for the further practical designing and researching.

(2) In the second stage, i.e., the specialized course teaching stage of electrical engineering, we specially offer comprehensive laboratory course of electrical engineering, which, combined with production practice in electric power enterprise, lets undergraduates master basic engineering knowledge in electrical engineering, including engineering graphics reading and plotting, line connecting, equipment adjusting, and maintenance. In addition, in the important specialized courses teaching such as power engineering and high voltage engineering, we carry out bilingual teaching to train students' English applying ability, improve students' comprehensive quality, and provide them with more chances to contact international and latest knowledge system in electrical engineering field.

(3) In the third stage, after finishing specialized courses of electrical engineering, we offer electrical control technology applying designing and electrical engineering comprehensive designing, with both of them oriented to actual engineering problem of power enterprise. In this stage, guide students to combine theoretical analysis with engineering designing, improving their comprehensive applying ability. And students are also required to master the frequently used electrical engineering analysis and designing soft wares such as: PASAP, Saber, Ansoft, etc, laying good foundation for graduation designing and enterprise engineering practice.

\section{- Comprehensive Engineering Ability Training Layer}

(1) Cooperative training by enterprise cooperation. Employ senior engineers with luxuriant theoretical and practical experiences in power enterprise cooperation as part-time teachers. Through regular special lectures and technology training, they explain talent requirement and development trend in power industry, introduce latest national and international power industry standardization, strengthening students' modern engineering design consciousness. (2) Set up training base in cooperative enterprise, which provides students with a chance to practice in power enterprise, 


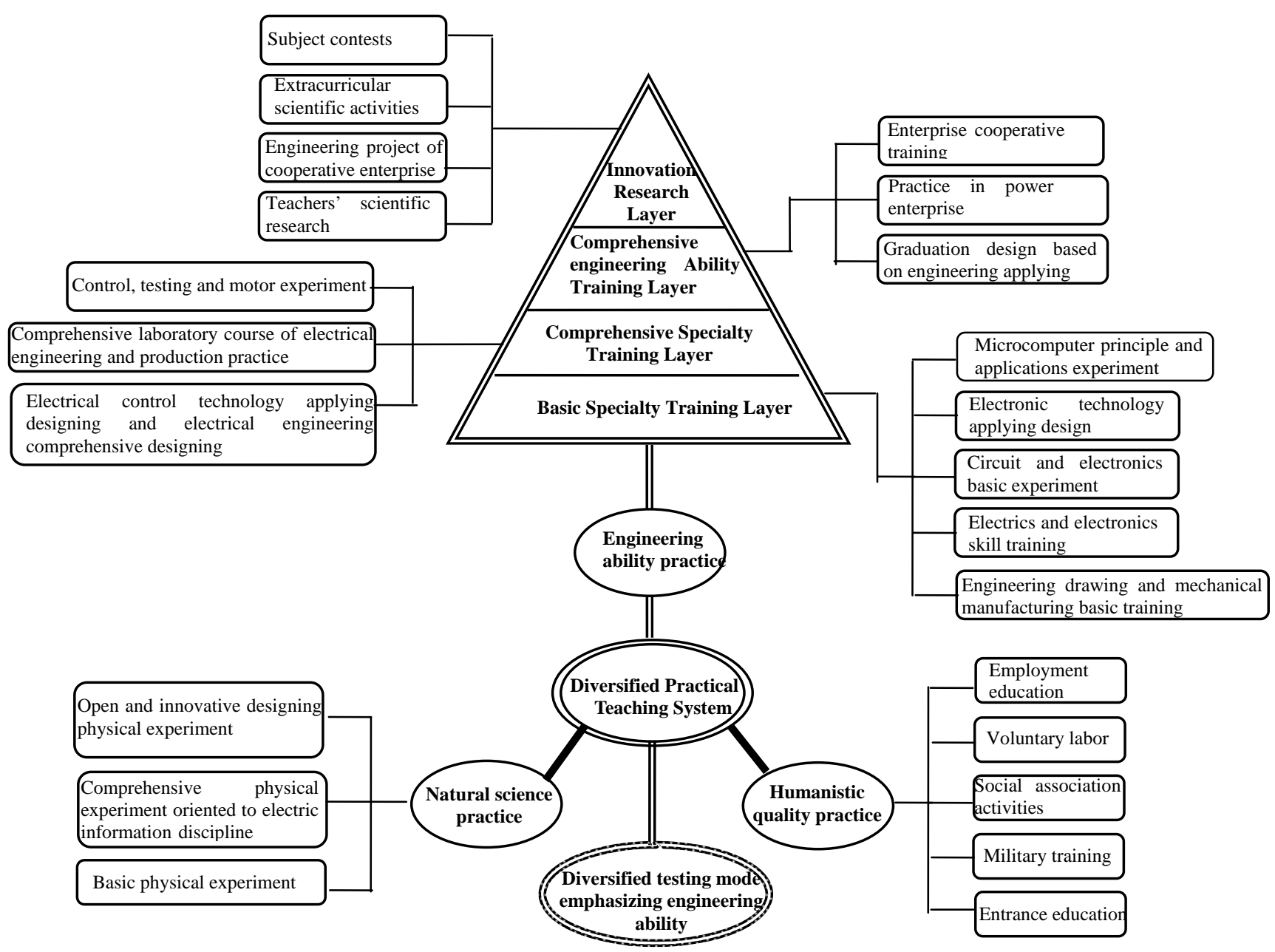

Figure.1 Diversified and Multilevel Practical Teaching System based on Engineering Ability Cultivation

letting them have preliminary knowledge and skill of actual project designing, developing, and managing. Currently, the cooperative enterprises of electrical engineering specialty in our university, including Chongqing electric power company, Chongqing Hydraulic Turbine factory, Chongqing Wanzhou hydraulic and power group, etc., can provide our third grade students with several paid practice positions each year. (3) Graduation designing based comprehensive engineering ability training. Increase the proportion of engineering applying titles of graduation design, and adopt project-driving mode aiming at actual engineering problem and related developing project. The power enterprise offer the needed spot data, technique and experimental equipment similar to these used in actual engineering designing, all of the above connecting graduation designing with practical engineering. In the whole graduation designing course, create conditions to cultivate students' engineering ability and innovative conscience, letting them gradually have various knowledge and ability of product researching and designing, practical working, expressing ability, team cooperation and professional morality,etc.

\section{- Innovation Research Layer}

(1) Actively run various types of subject contests and extracurricular scientific activities for university students, such as National Undergraduate Electronic Design Contest, National "Challenge Cup" Science and Technology Competition, and other science and technology competition activities organized by our university, all of these providing favorable studying, designing and researching environments for students of different levels. (2) From the second university year, select some excellent students to take part in teachers' scientific research project or actual project of cooperative enterprise, letting them become familiar with power enterprise's 
project developing course and various developing and managing regulations, and furthermore training their innovative conscience and ability of product designing and technical reform in a higher level.

\section{- Diversified testing mode emphasizing engineering ability}

The testing is converted from focusing on "testing result" to focusing on "practical course" and "engineering ability”, adopting individualized manage mode to encourage students' learning initiative and creative consciousness. We reform traditional testing mode of mainly paying attention to written report, adopting diversified testing mode. According to different practical item, the students are required to hand in practical experience report, investigating report, engineering analysis report, technical innovation proposal, or product designing plan, engineering project implementing scheme, actual designed product and other materialized achievements. In addition, the testing result needs to consider students' organization and team collaboration ability shown in the practical course.

\section{Conclusions}

Through constructing the practical teaching system including humanity quality practice, natural science practice and engineering ability practice, students can acquire omnidirectional, personalized and multiform trainings, with their engineering abilities cultured at different degree. As a result, talent quality has been improved, and the degree of approval of talent training for electrical engineering specialty in our university is rising continually.

But practical teaching system reform based on engineering ability training is a gradual course. From Sep. 2010, as the first experimental specialty in our university, the electrical engineering specialty begun to implement "Excellent engineer plan" by the University-Industry Cooperation platform collaborated with domestic high-level power enterprise. Each year, we openly select 20 excellent students to take part in this plan, and every one of them could have chance to study and work in these high level enterprises for one year. Currently, the "Excellent engineer plan" is still on the way of progress and exploration, and we hope to systematically expand this plan to all the students of electrical engineering step by step in the future. Then, in a real sense, we can realize a diversified and multilevel practical teaching system focusing on engineering ability cultivation, training more and better qualified engineering talent of electrical engineering specialty.

\section{References}

[1] W Ming, X Guangjing, “Study on competence-oriented engineering education reform”, Journal of Technology College Education, vol.3, pp. 54-59, 2010.

[2] L Zhengxiang, "Engineering education major certification and its influence on university practical teaching”, Laboratory Research and Exploration, vol.6, pp. 1-3, 2008.

[3] Z Hailin, Z Binsheng, H Aiping, Ge Leton, "Exploring the system for cultivating engineering students' engineering ability”, Journal of Jiangsu Polyetchnic University: Social Science Edition, vol.4, pp. 69-72, 2008.

[4] W xiuye, Q Hui, "Construction practical teaching system of automation specialty", China Electric Power Education, vol126, pp. 133-134, 2008.

[5] W Cunwen, O Qiong, "The construction and practice of new education approach in colleges of engineering”, Higher Education in Chemical Engineering, vol.5, pp. 67-70, 2008.

[6] W Guihe, L Jianguo, J Cangqin, G Puhai, L Guomin, "Establishing new type platform of engineering practice and strengthening engineering ability training”, Chinese Geological Education, vol.3, pp. 69-73, 2009 